\title{
DRIVING ASSESSMENT AND SUBSEQUENT DRIVING OUTCOME: A PROSPECTIVE STUDY OF SAFE AND UNSAFE HEALTHY DRIVER GROUPS
}

\author{
Petra Hoggarth ${ }^{1,2}$, Richard Jones ${ }^{1,3,4}$, Carrie Innes ${ }^{1,3}$ \& John Dalrymple-Alford ${ }^{1,2}$ \\ ${ }^{1}$ Van der Veer Institute for Parkinson's \& Brain Research \\ ${ }^{2}$ Dept Psychology, University of Canterbury \\ ${ }^{3}$ Dept Medical Physics \& Bioengineering, Christchurch Hospital, \\ ${ }^{4}$ Dept Medicine, University of Otago \\ Christchurch, New Zealand \\ E-mail: petra.hoggarth@vanderveer.org.nz
}

\begin{abstract}
Summary: Older drivers are an increasingly numerous section of the population who are often targeted for driving assessment. Little is known as to whether onroad driving assessments result in an older driver population who have fewer negative driving events. Fifty-eight healthy older drivers (mean age 77, range 7184, no diagnosis of neurological disorder), completed a non-enforced on-road driving assessment and detailed sensory-motor and cognitive testing. Selfreported and official data regarding crashes and traffic offences were collected for both the five years prior to the on-road assessment, and the 12 months following in order to determine whether those who received a Fail score on the on-road assessment had higher rates of negative driving events than those who passed (43 passed, 15 failed). No increase in adverse outcomes was found either retrospectively or prospectively for those who failed the on-road assessment. Similarly there were no significant differences in cognitive, sensory-motor, and demographic variables between those who passed and failed. Healthy older drivers who failed the on-road assessment did not show evidence of poorer driving behaviour even at the level of descriptive statistics.
\end{abstract}

\section{INTRODUCTION}

Older drivers are a rapidly growing section of the population at increased risk of being injured and killed in car accidents (McKnight \& McKnight, 1999; OECD, 2001). Health concerns linked to unsafe driving in older drivers include chronic physical conditions (Dobbs, Caprio Triscott, \& McCraken, 2004; Marottoli, Cooney, Wagner, Doucette, \& Tinetti, 1994), visual attention and processing deficits (Ball \& Owsley, 1991, 1996), and age-related cognitive decline and dementia (Cooper, Tallman, Tuokko, \& Beattie, 1993; Dobbs, Heller, \& Schopflocher, 1998; Johansson et al., 1996; McKnight \& McKnight, 1999). As the percentage of older drivers in the population increases it is becoming increasingly important to have reliable and valid assessment tools to assess driving ability in this group.

Driving assessors regularly use both off- and on-road measures to assess driving ability (KornerBitensky, Bitensky, Sofer, Man-Son-Hing, \& Gelinas, 2006). Off-road measures range from tests of visual acuity, neuropsychological tests, computerized cognitive test batteries, and complex driving simulators. On-road driving assessments are generally used as the "gold standard" measure of driving safety and often serve as the dependent variable in studies attempting to find 
predictors of driving safety. However, it has also been suggested that on-road assessments act as proxies for more critical measures, such as adverse driving outcomes in real-world driving situations (Owsley, Ball, Sloane, Roenker, \& Bruni, 1991).

Many countries and states impose some degree of age-based testing on older drivers. For example, California requires a vision and written knowledge test at age 70, while New Jersey has no age-based requirements for licence retention. In New Zealand a compulsory on-road assessment was required for drivers aged 80 and above prior to 2006. These older New Zealand drivers were 1.33 times more likely to be involved in an injury-causing accident in the following two years for every time that the test had to be re-sat in order to secure a pass (Keall \& Frith, 2004). This evidence suggests that the on-road driving test outcome is related to actual on-road driving outcomes. After 2006 the on-road assessment was abolished and the responsibility for detecting driving problems in older drivers fell solely to general practitioners who are charged with providing a medical certificate at age 75,80 , and biennially thereafter for drivers to retain their licence. This prompted a study to determine what sensory-motor, cognitive and demographic variables were associated with real-world driving outcomes in a group of older drivers with no neurological impairment.

The current study is a 12-month follow-up of 58 drivers aged 70 years and over who were tested off-road on a range of sensory-motor and cognitive tests and on an on-road driving assessment with a Pass or Fail outcome. Participants were volunteers with no repercussions for receiving an on-road Fail score. This provided a unique opportunity to follow the driving behaviour of a group of drivers deemed a priori to be safe or unsafe. Firstly, the relationship between officiallyreported retrospective traffic offences in the five years prior to the on-road assessment were compared to Pass and Fail on-road outcomes. Next, on-road Pass and Fail outcomes were compared to prospective officially- and self-reported crashes and traffic offences. The results of the initial off-road sensory-motor and cognitive testing were also compared to prospective crashes and traffic offences.

\section{METHOD}

\section{Participants}

Participants were 58 drivers (50\% male) aged $71-84$ years (mean $=77.5, \mathrm{SD}=4.2)$. They were a convenience sample recruited from a variety of community groups (e.g., churches, recreational groups), word of mouth, and advertisements placed in older-person's and health-oriented magazines distributed free in Christchurch, New Zealand. Exclusion criteria included a history of moderate to severe brain injury, neurological disease, and current psychiatric disorder. Inclusion criteria were chosen to reflect those older drivers who would likely be considered low-risk due to a lack of diagnosed neurological disease and would likely receive a medical fitness to drive certificate without referral for specialist driving assessment. Forty-three participants received a Pass on the on-road driving assessment and 15 received a Fail (25.9\%). Both the initial and current studies were approved by the Upper South A Regional Ethics Committee. 


\section{Off-Road Assessment}

Participants completed a number of cognitive tests including an IQ estimate (the Wechsler Test of Adult Reading, Wechsler, 2001), a standardized version of the Mini-Mental State Examination (Molloy \& Standish, 1997), the Dementia Rating Scale-2 (Mattis, Jurica, \& Leitten, 2001), Trail Making Test A and B, and a letter cancellation task. Visual acuity in each eye was also assessed using a Snellen chart. Participants also underwent assessment on a computerized battery of sensory-motor and cognitive tests (SMCTests) (Innes, Jones, Anderson, Hollobon, \& Dalrymple-Alford, 2009; Jones \& Donaldson, 1995; Jones, Donaldson, \& Parkin, 1989) developed as a research tool for assessment of patients with neurological disorders and for assessment of driving ability (Innes et al., 2007). SMCTests assesses visuospatial function, visuoperception, reaction time, ballistic movement, visuomotor tracking, decision-making, visual search, sustained attention, divided attention, impulse control, and planning. Test stimuli were presented on a computer monitor and responses recorded using a face-valid system comprising a steering wheel, direction indicators, and a set of foot pedals (Figure 1).

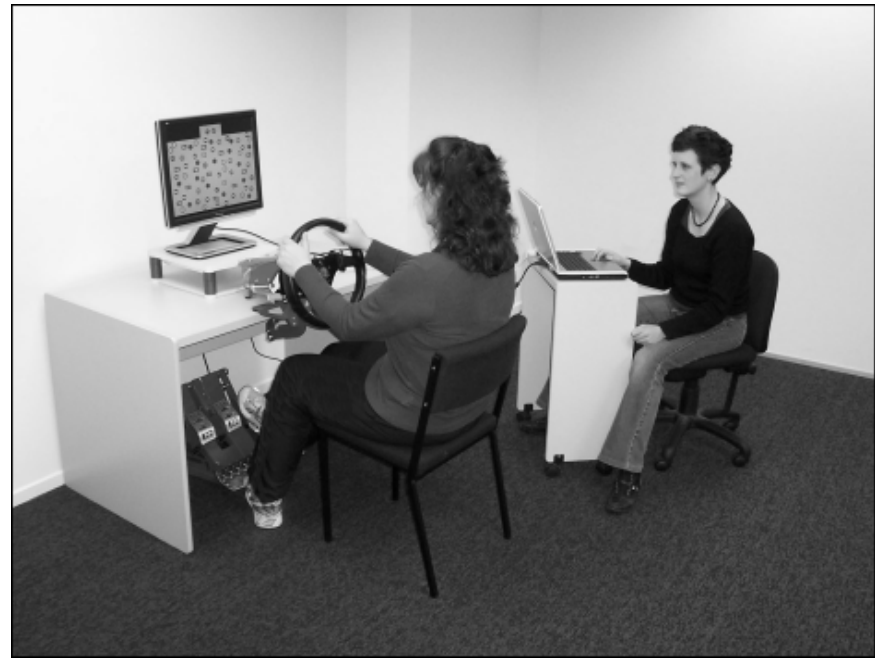

Figure 1. SMCTests apparatus

\section{On-Road Assessment}

An on-road driving assessment was administered by a specialist occupational therapist and a driving instructor, both of whom were blind to performance on off-road testing. Participants drove the same 45-min route. Conditions included driving on public roads with traffic hazards such as single-lane roundabouts, dual-lane roundabouts, dual-lane roads, controlled and uncontrolled intersections, and changes in speed zone (i.e., $50 \mathrm{~km} / \mathrm{h}, 60 \mathrm{~km} / \mathrm{h}$, and $80 \mathrm{~km} / \mathrm{h}$ sections). The assessors provided a consensus Pass or Fail score based on an 11-point Driving Scale (Innes et al., 2007).

\section{Officially-Recorded Traffic Offences and Crashes}

The New Zealand Transport Agency provided information regarding traffic offences for the period January 2002 through December 2008. This covers approximately 5 years prior to the onroad driving assessment until the completion of the 12 month follow-up period. Examples of the 
potential types of offences recorded are speeding, driving while intoxicated, reckless driving, and violating posted traffic signs. The New Zealand Ministry of Transport provided information for the same time period regarding police-reported injury crashes.

\section{Follow-up Interview}

Participants were interviewed by telephone 1 year $(\mathrm{SD}=8.0$ days $)$ after their on-road driving assessment. They were asked to report the number of crashes and traffic offences committed during the 12 months following their assessment. Self-report was used to capture crashes not attended by police and traffic offences not reflected in Land Transport New Zealand data. For example, official data does not cover speed camera tickets. Speed camera tickets are issued by unattended speed radar detectors that photograph vehicle licence plates which are used to identify and post fines to registered owners of speeding vehicles.

\section{Data Analysis}

Fisher's Exact Test was used to determine whether the presence of an officially-reported traffic offence in the five years prior to the on-road assessment was different between subsequent onroad Pass or Fail outcome. The difference between Pass and Fail outcomes and officially- or selfreported traffic offence or crashes prospectively over 12 months was investigated in the same way. Data was then regrouped into those who had and had not had any reported crash or traffic offence in 12 months since their on-road driving assessment, and group membership was compared to scores on the initial sensory-motor and cognitive tests, and demographic data using $t$ tests for normally distributed data and Mann-Whitney $U$ tests for non-normally distributed data. The existence of at least one officially- or self-reported crash or offence was coded as a binary value for each participant.

\section{RESULTS}

At the first-12 month follow-up, 57 of 58 participants were still driving. One participant had ceased driving for several months due to a non-driving related injury but was intending to drive again when medically possible.

\section{Officially-reported retrospective crashes and traffic offences}

There were no officially-reported crashes in the five years prior to the on-road assessment. There were seven officially-reported traffic offences committed by six participants (one committed two offences) (Table 1). All seven traffic offences were for exceeding a posted speed limit of either $50 \mathrm{~km} / \mathrm{h}$ or $100 \mathrm{~km} / \mathrm{h}$. All offences were committed by participants who went on to Pass the onroad assessment. There was no difference in the number of traffic offences reported between onroad Pass and Fail groups (Fisher's Exact Test, two-tailed $p=.15$ ).

\section{Officially and self-reported traffic offences and crashes in subsequent 12 months}

There were nine traffic offences across eight drivers in the 12-month period following the onroad assessment. Five offences were self-reported only (e.g., fixed camera speeding violations). 
Three offences were both officially- and self-reported, and one was officially reported only. Two of the participants who committed an offence received an on-road Fail score (Table 1).

There were four self-reported crashes across four drivers, with none officially recorded. None of the people who reported crashes also had self- or officially-reported traffic offences. Only one of the accidents was committed by a driver who received an on-road Fail score.

There was no difference in the number of traffic offences or crashes between on-road Pass and Fail groups (Fisher's Exact Test, two-tailed $p=.63$ ).

Table 1. Number of participants with one or more retrospectively or prospectively reported crashes or offences (number in Pass and Fail on-road group)

\begin{tabular}{lcc}
\hline & \multicolumn{2}{c}{ Type of traffic event } \\
\cline { 2 - 3 } & Participants with Crashes & Participants with Offences \\
\hline Retrospective (5 yr) & 0 & 6 (0 Fail, 6 Pass) \\
Prospective (12 mo) & 4 (1 Fail, 3 Pass) & 8 (2 Fail, 6 Pass ) \\
\hline
\end{tabular}

\section{Sensory-motor, cognitive, and demographic predictors of crashes and offences in subsequent 12 months}

There were no significant differences found in sensory-motor and cognitive test performance and demographics between the 12 participants who experienced a crash or traffic offence in the 12 months following the off-road assessment and the remaining 46 who did not.

\section{DISCUSSION}

This is the first study to follow a group of older drivers a priori judged to be safe or unsafe based on a comprehensive on-road driving assessment. No relationship was found either between retrospective or prospective crashes and traffic offences and the on-road Pass or Fail score. Additionally, no relationship was found between cognitive and sensory-motor measures and prospective crashes and traffic offences. The lack of discernable differences in real-life driving between the 'safe' and 'unsafe' driver groups highlights difficulties in predicting driving safety. Research has shown that loss of a driver's licence in the elderly is associated with loneliness and immobility (Johnson, 1999). The low base-rate of traffic offences and crashes makes decisions regarding forfeiture of licences particularly fraught when the likely harm to the older driver versus harm to the community are taken into consideration.

Langford, Bohensky, Koppel, and Newstead (2008) recently compared driving fatalities of older drivers across two Australian states, one with compulsory medical and on-road assessments for drivers aged 80 and above, and one with no testing requirement. They found no difference in the number of fatalities of older drivers or other road users and concluded that age-based testing shows no demonstrable safety benefits. Another possibility for this result is that the on-road assessment used was not sensitive to the factors that predict real-world driving and those who had their licences forfeited were not more dangerous than those who did not. Another large sample study of older drivers found significant cognitive test predictors of prospective at-fault crashes over a period of five years (Ball et al., 2006). However, the driving ability of the 
participants in this study had not been assessed by the authors a priori. Allowing drivers judged to be unsafe using an on-road driving assessment to continue driving, as was the case in the present study, has to the best of our knowledge not been done in driving research literature. Thus the study provides a unique perspective on how dangerous those considered to be unsafe really are, beyond that provided by comparing populations with and without compulsory testing, or by relying solely on an on-road assessment to define safety. Had the results of the on-road assessments been disseminated to participants' doctors, 15 participants could have had their licences revoked. This equates to 15 participants who would have been left without personal transportation and the associated difficulties this imposes, and yet there were no differences in traffic incidents even at the level of descriptive statistics.

One weakness of the study is the relatively small number of participants and the low base-rate of crashes and offences. This weakens our ability to find significant differences between groups. Given the serious personal consequences for an older driver losing their licence, however, we should expect that those judged to be unsafe following a driving assessment should have noticeable increases in crashes and/or offences even at the level of descriptive statistics. Another weakness of the study is that the validity of the on-road assessment is unknown, despite similar assessments being routinely performed to assess driver safety throughout New Zealand and around the world. While a 24-month follow-up of this group which will provide additional data regarding driver safety is planned, the current 12-month data allows no discrimination between safe and unsafe groups.

\section{ACKNOWLEDGEMENTS}

The authors would like to acknowledge funding for this project from the Transport Research and Educational Trust Board, Accident Compensation Corporation, Christchurch Neurotechnology Research Programme, and University of Canterbury. This research was supported (in part) by a contract from the Health Research Council of New Zealand.

\section{References}

Ball, K. K., Roenker, D. L., Wadley, V. G., Edwards, J. D., Roth, D. L., McGwin, G., Raleigh, R., Joyce, J. J., Cissell, G. M., \& Dube, T. (2006). Can high-risk older drives be identified through performance-based measures in a Department of Motor Vehicles setting? Journal of the American Geriatrics Society, 54, 77-84.

Cooper, P. J., Tallman, K., Tuokko, H., \& Beattie, B. L. (1993). Vehicle crash involvement and cognitive deficit in older drivers. Journal of Safety Research, 24, 9-17.

Dobbs, A. R., Caprio Triscott, J. A., \& McCraken, P. N. (2004). Considerations for assessment of medical competence to drive in older patients. Geriatrics and Aging, 7, 42-46.

Dobbs, A. R., Heller, R. B., \& Schopflocher, D. (1998). A comparative approach to identify unsafe older drivers. Accident Analysis \& Prevention, 30, 363-370.

Innes, C. R. H., Jones, R. D., Anderson, T. J., Hollobon, S. G., \& Dalrymple-Alford, J. C. (2009). Performance in normal subjects on a novel battery of driving-related sensory-motor and cognitive tests. Behavior Research Methods, 42, 284-294. 
Innes, C. R. H., Jones, R. D., Dalrymple-Alford, J. C., Hayes, S., Hollobon, S., Severinson, J., Smith, G., Nicholls, A., \& Anderson, T. J. (2007). Sensory-motor and cognitive tests can predict driving ability of persons with brain disorders. Journal of the Neurological Sciences, 260, 188-198.

Johansson, K., Bronge, L., Lungberg, C., Persson, A., Seiderman, M., \& Vittanen, M. (1996). Can a physician recognize an older driver with increased crash risk potential? Journal of the American Geriatrics Society, 44, 1198-1204.

Johnson, J. E. (1999). Urban older adults and the forfeiture of a driver's license. Journal of Gerontological Nursing, 25, 12-18.

Jones, R. D., \& Donaldson, I. M. (1995). Fractionation of visuoperceptual dysfunction in Parkinson's disease. Journal of the Neurological Sciences, 131, 43-50.

Jones, R. D., Donaldson, I. M., \& Parkin, P. J. (1989). Impairment and recovery of ipsilateral sensory-motor function following unilateral cerebral infarction. Brain, 112.

Keall, M. D., \& Frith, W. J. (2004). Association between older driver characteristics, on-road driving test performance, and crash liability. Traffic Injury Prevention, 5, 112-116.

Korner-Bitensky, N., Bitensky, J., Sofer, S., Man-Son-Hing, M., \& Gelinas, I. (2006). Driving evaluation practices of clinicians working in the United States and Canada. American Journal of Occupational Therapy, 60, 428-434.

Langford, J., Bohensky, M., Koppel, S., \& Newstead, S. (2008). Do age-based mandatory assessments reduce older drivers' risk to other road users? Accident Analysis \& Prevention, 40, 1913-1918.

Marottoli, R. A., Cooney, L. M., Wagner, D. R., Doucette, J., \& Tinetti, M. E. (1994). Predictors of automobile crashes and moving violations among elderly drivers. Annals of Internal Medicine, 121, 842-846.

Mattis, S., Jurica, P. J., \& Leitten, C. L. (2001). Dementia Rating Scale - 2. Lutz, Florida: Psychological Assessment Resources, Inc.

McKnight, A. J., \& McKnight, A. S. (1999). Multivariate analysis of age-related driver ability and performance deficits. Accident Analysis and Prevention, 31, 445-454.

Molloy, D. W., \& Standish, T. I. M. (1997). A guide to the Standardized Mini-Mental State Examination. International Psychogeriatrics, 9 (Suppl. 1), 87-94.

OECD. (2001). Ageing and transport: mobility and safety issues. Paris: OECD Publications.

Owsley, C., Ball, K., Sloane, M. E., Roenker, D. L., \& Bruni, J. R. (1991). Visual/cognitive correlates of vehicle accidents in older drivers. Psychology and Aging, 6, 403-415.

Wechsler, D. (2001). Wechsler Test of Adult Reading. San Antonio, Texas: Pearson Education, Inc. 